\title{
A study exploring knowledge, attitudes and behaviours towards autism among adults applying to a Family Health Center in Istanbul
}

\author{
Aysen Surmen ${ }^{1}$, Seyhan Hidiroglu ${ }^{1}$, Hamide Hande Usta ${ }^{1}$, Muhammed Awiwi ${ }^{1}$, \\ Ahmet Saki Oguz ${ }^{1}$, Melda Karavus ${ }^{1}$, Ahmet Karavus ${ }^{2}$ \\ ${ }^{1}$ Department of Public Health, Marmara University Faculty of Medicine, Istanbul, Turkey \\ 2Department of Otorhinolaryngology, Fatih Sultan Mehmet Training and Research Hospital, Istanbul, Turkey
}

\begin{abstract}
OBJECTIVE: The aim of this study was to assess knowledge, awareness, behavior and attitudes towards autism among applicants to a Family Health Center (FHC).

METHODS: This descriptive study was performed at a Family Health Center (FHC) in Istanbul in August 2013. Data was obtained via face-to-face interviews with participants older than 18 years who were admitted to the FHC. The questionnaire consisted of questions on sociodemographic characteristics, applicants' knowledge of autism and their approach to autism.
\end{abstract}

RESULTS: 160 applicants participated in our survey of which 38.8\% had heard the word 'autism'. Knowledge and awareness of autism, and attitudes and behaviours towards this disorder differed significantly with the educational level of the study participants $(p<0.05)$ However, these parameters did not change with gender and income level of the participants $(p>0.05)$.

CONCLUSION: The most important outcome of our study is that awareness, or even having knowledge of the word autism is significant in breaking down stereotypes. Despite the low level of awareness of the disease, the majority of the participitants had a positive attitude towards autism.

Key words: Autism; awareness; education; knowledge.

A utism disorder was first described in 1943 by the American child psychologist, Leo Kanner. He presented 11 children whose behaviours were obviously different from those of others. Kanner suspected that they had an inborn feature which had prevented their regular social contacts. Autism disorder is sometimes referred as early infantile au- tism, childhood autism or Kanner's autism [1].

Autism is a disorder of neural development, characterized by impaired social interaction, communication, and by restricted, repetitive behaviors. This condition onsets at birth or within the first two-and-a-half years of life [2]. Even though behavioural differences become manifest before the age of

Received: December 05, 2014 Accepted: March 16, 2015 Online: April 24, 2015

Correspondence: Dr. Aysen SURMEN. Marmara Universitesi Halk Sagligi Anabilim Dali, Maltepe Basibuyuk Kampusu, Maltepe, Istanbul, Turkey.

Tel: +90 216 - 4212222 e-mail: aysurmen@hotmail.com

(c) Copyright 2015 by Istanbul Northern Anatolian Association of Public Hospitals - Available online at www.kuzeyklinikleri.com 
2 , diagnosis is usually made at 3 years of age or above [3]. Although etiology, and pathogenesis are not fully acknowledged, and completely elucidated, various genetic, prenatal, early postnatal, microbiological, biochemical, and environmental factors have been implicated in the etiopathogenesis of autism $[4,5]$.

In the last decade, the prevalence of autism had risen dramatically. Based on CDC (Centers for Disease Control, and Prevention) estimates from 2009 autism is seen in 1 of every 110 children. The CDC has recently reported an increase in the estimates up to 1 in every 88 children, acknowledging that "the extent to which these increases reflect better case ascertainment whether as a result of increases in awareness and access to services or true increases in the prevalence of autism spectrum disorder (ASD) symptoms is not known" [6].

Probable causes of increases in prevalence include expanded diagnostic criteria, and increased awareness of the disease [7]. Knowledge and awareness of the condition have grown exponentially at all levels among general public, parents, health professionals, research community and more recently, at a parliamentary level [8]. The World has begun to recognize the scope of this problem and acted internationally and locally to improve the lives of the growing number of individuals and families affected by this devastating disorder [1].

Nowadays, diagnosis of autism has been more frequently made. Early diagnosis is quiet important with respect to rehabilitation alternatives, and longterm responses [6]. In the early diagnosis, knowledge level, and awareness of the public carry utmost importance. Our aim in this study is to evaluate knowledge levels, attitudes, behaviours and awareness of adults about autism who consulted to FHC for any symptom.

This study was carried out on 160 adults applying to a Family Health Center in Istanbul aiming to investigate their awareness about autism.

\section{MATERIALS AND METHODS}

The study was designed as a descriptive study. This questionnaire study was realized in a FHC in a county of Istanbul in August 2013 after approval from the Ethics Committee was obtained. Patients, their intimates, and attendants aged over 18 were informed about the study, and those volunteered to participate in the study were enrolled in the study after their verbal approvals were obtained. Data were gathered during face-to-face interviews. The questionnaire forms applied for participants contained a total of 62 questions aiming at determination of sociodemographic characteristics $(n=5$ questions), knowledge levels of the participants about autism ( $n=49$ questions prepared based on DSM-IV diagnostic criteria), and their attitudes towards autism ( $\mathrm{n}=8$ questions).

For statistical analysis of data SPSS 17.0 program was used. In descriptive analysis, data were expressed as frequencies, ratios and means. In intergroup comparisons for categorical variables, Kolmogorov-Smirnov and chi-square tests were used. The results were evaluated at accepted level of significance of $\mathrm{p}<0.05$, and within $95 \%$ confidence interval.

Since our study was performed within a limited time period on adult patients applied to only one FHC, we can not generalize the results obtained for the population in general.

\section{RESULTS}

A total of 160 individuals (female, $\mathrm{n}=99 ; 61.9 \%$, and male, $n=61 ; 38.1 \%$ ) with a mean age of $34.5 \pm 12.5$ years participated in the study. The participants were illiterate $(28.2 \%)$, primary $(28.8 \%)$, secondary school, and high school (42.5\%), and university (11.9\%) graduates. Monthly income of the participants was $0-1000$ (11.9\%), 1001-3000 (73.6\%), and $\geq 3001(14.4 \%)$ Turkish liras. Four participants had autistic patients in their families, while 18 participants had close friends with autism. Sixtytwo $(38.8 \%)$ participants heard the word 'autism' (female, 37\%, and male, 41\%). A statistically significant correlation was not found between gender, income level, and the number of participants who heard the word 'autism' ( $p>0.05)$. A statistically significant correlation was found between educational level, and the number of participants who heard the 
word 'autism' $(\mathrm{p}<0.05)$ (Table 1$)$.

When participants who heard the word 'autism' were asked about the diagnosis of autism, they described autism as a kind of mental retardation (46.8\%), a social communication gap (27.4\%), a speech disorder (12.9\%), weird repetitive movements $(8.1 \%)$, and $4.8 \%$ of them said that they had no idea about it.

Having heard about the word 'autism', and knowing its characteristics were compared, and those who heard the word 'autism' frequently responded affirmatively to the questions about autism, while participants who hadn't heard this word responded on the contrary. The difference between these two groups was statistically significant $(p<0.05)$. The participants who heard the word 'autism' (48.4\%) were asked to choose the accurate definition of autism". The individuals with autism had distinct nonverbal behavioural disorders involving eye contact with people, facial gestures, and expression, body postures, and body language they use during their social interactions. However a statistically significant difference was not detected between participants who heard or didn't hear the word 'autism' regarding responses to the questions concerning etiology of autism, potentially related health problems, subjective field, gender difference and curability of autism with treatment.
In our investigation, statistically significant differences were not found between opinions of participants about patients with autism, and either gender or income level $(p>0.05)$.

When responses to questions inquiring attitudes towards autism including 'Do you feel anxious when your neighbour next door is an autistic patient?' were compared, participants who heard about autism $(p=0.304)$, and those with higher level of education $(p=0.001)$ responded more frequently as 'No, I don't mind (Table 2).

The response 'I don't feel uneasy if an autistic person is working in my workplace' was given by 50 , and $29.6 \%$ of the participants who heard, and did not hear the word 'autism' respectively $(\mathrm{p}=0.045)$. The question 'Do you mind if your child share the same classroom with an autistic child?' was responded negatively by 36 participants, while a statistically significant difference was not found between responses of the study subjects who heard, and did not hear the word 'autism' ( $p=0.282)$. As educational level increases, the number of people who responded affirmatively also increases statistically significantly $(p<0.001)$ (Table 3$)$. Higher number of people who heard the word 'autism' said that if an autistic person sits next to them in the bus, they would not change their place or scare when compared to those who didn't know this word $(\mathrm{p}<0.05)$.

\begin{tabular}{|c|c|c|c|c|c|c|c|}
\hline \multirow[t]{3}{*}{ Educational level } & \multicolumn{6}{|c|}{ Awareness of autism } & \\
\hline & \multicolumn{2}{|c|}{ Yes } & \multicolumn{2}{|c|}{ No } & \multicolumn{2}{|c|}{ Total } & \\
\hline & $\mathrm{n}$ & $\%$ & $\mathrm{n}$ & $\%$ & $\mathrm{n}$ & $\%$ & \\
\hline Illiterate & 0 & 0 & 9 & 100.0 & 9 & 100 & $\mathrm{a} p<0.001$ \\
\hline Literate & 5 & 27.8 & 13 & 72.2 & 18 & 100 & ${ }^{a} x^{2}$ \\
\hline Primary school & 10 & 21.7 & 36 & 78.3 & 46 & 100 & \\
\hline Secondary school & 12 & 33.3 & 24 & 66.7 & 36 & 100 & \\
\hline High school & 19 & 59.4 & 13 & 40.6 & 32 & 100 & 24.456 \\
\hline University & 16 & 84.2 & 3 & 15.8 & 19 & 100 & \\
\hline Total & 62 & 38.8 & 98 & 61.2 & 160 & 100 & \\
\hline
\end{tabular}

a: Kolmogorov-Smirnov test was used; $D_{\max }: 0.401$. 
TABLE2. Approach to autism according to educational level of the participants, and autism awareness

Do you worry if your neighbour were an autistic individual?

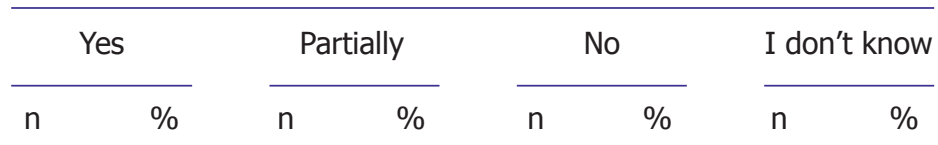

\begin{tabular}{|c|c|c|c|c|c|c|c|c|c|}
\hline \multicolumn{10}{|l|}{ Have you heard of autism? } \\
\hline Yes $(n=62)$ & 14 & 22.6 & 14 & 22.6 & 31 & 50.0 & 3 & 4.8 & ${ }^{\mathrm{a}} \mathrm{p}=0.304$ \\
\hline No $(n=98)$ & 22 & 22.4 & 32 & 32.7 & 27 & 27.6 & 17 & 17.3 & ${ }^{a} x^{2}=2.377$ \\
\hline \multicolumn{10}{|l|}{ Educational level } \\
\hline Illiterate $(n=9)$ & 0 & 0.0 & 3 & 33.3 & 2 & 22.2 & 4 & 44.4 & ${ }^{b} p=0.001$ \\
\hline Literate $(n=18)$ & 6 & 33.3 & 3 & 16.7 & 5 & 27.8 & 4 & 22.2 & \\
\hline Primary school $(n=46)$ & 14 & 30.4 & 13 & 28.3 & 15 & 32.6 & 4 & 8.7 & ${ }^{b} x^{2}=22.680$ \\
\hline Secondary school $(n=36)$ & 9 & 25.0 & 14 & 38.9 & 7 & 19.4 & 6 & 16.7 & $\mathrm{DF}=6$ \\
\hline High school $(n=32)$ & 4 & 12.5 & 9 & 28.1 & 17 & 53.2 & 2 & 6.2 & \\
\hline University $(\mathrm{n}=19)$ & 3 & 15.8 & 4 & 21.1 & 12 & 63.2 & 0 & 0.0 & \\
\hline
\end{tabular}

a: Kolmogorov-Smirnov test was used and $D_{\max }: 0.125$; ${ }^{b}$ : Chi square test was used, $p$ value and $x^{2}$ values were estimated by integrating illiterate vs literate, primary vs secondary education, and High school vs university groups in a table with 3 rows.

In our investigation, study participants who heard the word'autism' responded affirmatively to the questions about their attitudes towards autistic persons, and most of these responses were statistically significant. This outcome can be interpreted as even having heard the word 'autism' effects the attitude towards autistic individuals positively $(p<0.05)$.

TABLE 3. Approach to autism according to educational level of the participants, and awareness about autism

Do you mind if your child share the same classroom with an autistic patient?

\begin{tabular}{|c|c|c|c|}
\hline Yes & Partially & No & I don't know \\
\hline$\%$ & $\%$ & $\%$ & $\%$ \\
\hline
\end{tabular}

Have you heard of autism?

\begin{tabular}{|c|c|c|c|c|c|c|c|c|c|}
\hline Yes $(n=62)$ & 13 & 21.0 & 10 & 16.1 & 32 & 51.6 & 7 & 11.3 & ${ }^{\mathrm{a}} \mathrm{p}=0.282$ \\
\hline No $(n=98)$ & 23 & 23.5 & 26 & 26.5 & 31 & 31.6 & 18 & 18.4 & ${ }^{a} x^{2}=2.529$ \\
\hline \multicolumn{10}{|l|}{ lucational level } \\
\hline Illiterate $(n=9)$ & 0 & 0.0 & 3 & 33.3 & 1 & 11.1 & 5 & 55.6 & \multirow[t]{2}{*}{${ }^{\mathrm{b}} \mathrm{p}<0.001$} \\
\hline Literate $(n=18)$ & 5 & 27.8 & 3 & 16.7 & 4 & 22.2 & 6 & 33.3 & \\
\hline Primary $(n=46)$ & 15 & 32.6 & 9 & 19.6 & 19 & 41.3 & 3 & 6.5 & ${ }^{b} x^{2}=25.693$ \\
\hline Secondary $(n=36)$ & 8 & 22.2 & 13 & 36.1 & 9 & 25.0 & 6 & 16.7 & $\mathrm{DF}=6$ \\
\hline High school $(n=32)$ & 4 & 12.5 & 4 & 12.5 & 20 & 62.5 & 4 & 12.5 & \\
\hline University $(\mathrm{n}=19)$ & 4 & 21.1 & 4 & 21.1 & 10 & 52.6 & 1 & 5.3 & \\
\hline
\end{tabular}

a: Kolmogorov-Smirnov test and Dmax: 0.129 ; ${ }^{b}$ : Chi square test was used, $\mathrm{p}$ value and $\mathrm{x}^{2}$ values were estimated by integrating illiterate vs literate, primary vs secondary education, and High school vs university groups in a table with 3 rows. 


\section{DISCUSSION}

Only $38.8 \%$ of the study participants heard the word'autism. In a study performed in France its incidence was 100 percent [9]. In a study, Wilson indicated that $69 \%$ of the parents had heard the word autism [10]. Although our study did not evaluate the socioeconomic level of the community fully, in our field of study which might be considered as a region of relatively lower socioeconomic level. Within this context, when compared with other similarly designed studies, relatively lesser number of our study participants who heard the word 'autism' might be associated with lower socioeconomic level of our study population.

In our study, $37 \%$ of women, and $41 \%$ of men had heard the word 'autism. In a study performed in France, higher incidence of awareness for autism was detected among women [9]. This difference might stem from educational level, and social status of female gender in our country. As educational level of the community increased, incidence of autism awareness significantly rised. Education contributes to the rising trends in autism awareness, and enables early diagnosis, and treatment among educated people, and their environment. Education can prevent prejudice against autistic individuals in the community. Majority of the participants stated that they wouldn't feel uneasy if an autistic individual was present in their environment, workplace or classroom of their children. This phenomenon might stem from favourable viewpoints of the participants about autism or their higher level of awareness.

The questions which evaluated reactions of the participants when they met autistic individuals including 'Do you scare or rise, and sit in another place when an autistic person sits next to you?' were responded as "No, I don't mind!" At the same time the questions 'Do you behave them as normal individuals? Do you feel pity for them?' were responded as 'Yes, I do' By higher majority of par ticipants. These affirmative responses demonstrate positive approaches of the participants. However the proper approach may be to emphatize with autistic individuals, and their families, and contribute to their social development. Indeed treatment of autistic in- dividuals will be possible by reintegrating them into the society. A study which integrates groups with and without autism in sportive, cultural, and art activities were observedly beneficial for both groups, and also contributed to alleviation of social, and communicative difficulties [11].

According to the results of our investigation, the individuals who heard the word 'autism' because of the presence of an autistic individual in their close environment, and those with higher educational level because of increased level of consciousness towards all diseases, may be less prejudiced towards autism. Besides they are more inclined to share the same social environment with them.

With these approaches, socialization of especially autistic children, and thus their treatment will be facilitated.

In conclusion, when perspectives and approaches of the participants towards autism were evaluated generally an affirmative outcome has been obtained. The most important outcome of our study is that even having heard the word'autism' has been statistically significantly effective in breaking prejudices against autism from many perspectives. This promising situation will cherish our hopes in that programs, and efforts aiming at initiation, promotion, and development of health education, which will be implemented so as to increase awareness, and consciousness towards autism will be welcomed favourably, and yield quick responses.

Conflict of Interest: No conflict of interest was declared by the authors.

Financial Disclosure: The authors declared that this study has received no financial support.

\section{REFERENCES}

1. J U, M M V, J P, Srinivasan I. Autism Disorder (AD): An Updated Review for Paediatric Dentists. J Clin Diagn Res 2014;8:275-9.

2. Arif MM, Niazy A, Hassan B, Ahmed F. Awareness of autism in primary school teachers. Autism Res Treat 2013;2013:961595.

3. Mandell DS, Novak MM, Zubritsky CD. Factors associated with age of diagnosis among children with autism spectrum disorders. Pediatrics 2005;116:1480-6. CrossRef

4. Bryson SE. Brief report: epidemiology of autism. J Autism Dev Disord 1996;26:165-7. CrossRef 
5. Herbert MR. Autism: A brain disorder or a disorder that affects the brain? Clin Neuropsychiatr 2005;2:354-79.

6. Manning-Courtney P, Murray D, Currans K, Johnson H, Bing N, Kroeger-Geoppinger K, et al. Autism spectrum disorders. Curr Probl Pediatr Adolesc Health Care 2013;43:2-11. CrossRef

7. King M, Bearman P. Diagnostic change and the increased prevalence of autism. Int J Epidemiol. 2009;38:1224-34. CrossRef

8. Dover CJ, Le Couteur A. How to diagnose autism. Arch Dis Child 2007;92:540-5. CrossRef

9. Durand-Zaleski I, Scott J, Rouillon F, Leboyer M. A first na- tional survey of knowledge, attitudes and behaviours towards schizophrenia, bipolar disorders and autism in France. BMC Psychiatry 2012;12:128. CrossRef

10. Wilson BN, Neil K, Kamps PH, Babcock S. Awareness and knowledge of developmental co-ordination disorder among physicians, teachers and parents. Child Care Health Dev 2013;39:296-300. CrossRef

11. Günayer Şenel H. Otizmli Bireylerle Akranlarının Spor ve Sanat Etkinlikleri Aracılığıyla Etkileşimde Bulundukları İki Örnek Uygulama. Özel Eğitim Dergisi 2009;10:65-72. 